\title{
PENGARUH MASA KERJA DAN BEBAN MENGAJAR TERHADAP KINERJA PROFESIONAL DOSEN PROGRAM STUDI PENDIDIKAN EKONOMI, FKIP UNIVERSITAS ISLAM RIAU
}

\author{
Mohamad Arief Rafsanjani \\ Prodi Pendidikan Ekonomi Akuntansi, Fakultas Keguruan dan IImu Pendidikan \\ Universitas Islam Riau \\ Riau, Indonesia \\ e-mail : ariefrafs@gmail.com
}

\begin{abstract}
Abstrak
Penelitian ini bertujuan untuk menjelaskan pengaruh variable masa kerja dan beban mengajar terhadap kinerja professional dosen di program studi pendidikan ekonomi FKIP UIR. Penelitian ini dilakukan pada 27 dosen tetap dan dosen luar biasa. metode analisa data yang digunakan adalah regresi ganda. Hasil penelitian menunjukan bahwa variable masa kerja berpengaruh positif signifikan terhadap kinerja professional dosen, sedangkan untuk variable beban mengajar berpengaruh negative signifikan terhadap kinerja professional dosen
\end{abstract}

Kata kunci: masa kerja, beban mengajar, kinerja professional

\begin{abstract}
This research purposes to explain the influence of work period and teaching duty to lecturer professional performance. The study was conducted on the lecturer with 27 samples. The method of analysis using regreesion. Based on the results of this research is that work periode has positive significanct effect to professional performance of lecturer, and teching duty has negative significant effect to professional performance of lecturer.
\end{abstract}

Keyword: work period, work duty, professional performance

\section{PENDAHULUAN}

Masa kerja merupakan lama seseorang bekerja pada bidang tertentu. Wijaya (1986:68) mengungkapkan bahwa masa kerja dapat memberikan kemahiran, sehingga makin lama orang bekerja dapat makin cakap dan terampil di bidang pekerjaan itu. Hall \& Louck (dalam Alim,2004:28) melaporkan hasil penelitiannya yang menunjukkan bahwa pengalaman mengajar berpengaruh terhadap penerapan pembaharuan pendidikan. Yelon (dalam Soeharto,1992:49) berdasarkan pengalaman-pengalaman dosen selama mengajar, seorang dosen akan mampu menginterpretasikan pengalaman barunya.

Wright (1936) menjelaskan teori learning curve menandai suatu gejala yang terjadi bila orang mengerjakan pekerjaan yang sama berulang kali akan meingkatkan produktifitas sebagai akibat dari bertambahnya pengalaman. Corlett \& Marcombe (1938) menemukan bahwa kelompok yang diberi pelatihan berulang kali menghasilkan perbaikan kinerja dibandingkan dengan kelompok tanpa perbaikan.

Selain masa kerja, salah satu factor yang mempengaruhi kinerja dosen adalah beban mengajar. Lisnayeti (2006) menyatakan bahwa beban kerja berhubungan dengan kinerja dosen. Beban kerja yang tinggi menyebabkan berkurangnya kesempatan dosen dalam menyiapkan materi, mempersiapkan metode dan media dalam pengajaran. Selain itu, beban mengajar yang tinggi juga menyebabkan berkurangnya waktu yang bisa digunakan dosen dalam 
meningkatkan kemampuan dan pengetahuan individu dosen itu sendiri, seperti kemampuan menguasai bahasa asing, waktu untuk mempersiapkan dan melaksanakan penelitian dan pengabdian kepada masyarakat. Menurut Legawati (1996:42), dosen yang mempunyai beban mengajar terlalu banyak dan melebihi ketentuan jam wajib yang telah diperhitungkan akan mempengaruhi daya tahan fisik dosen. Di samping itu dosen tidak sempat lagi mempersiapkan materi pengajaran secara sempurna yang pada gilirannya secara keseluruhan beban mengajar akan mempengaruhi kemampuan mengajarnya, karena pengajaran menjadi tidak terprogram dengan baik.

Tugas seorang dosen tidak hanya dibidang pengajaran, akan tetapi terangkum dalam tridarma perguruan tinggi yang terdiri dari pendidikan dan pengajaran, pengembangan ilmu dan pengabdian pada masyarakat ditambah kegiatan penunjang.

Beban tugas tenaga pengajar ialah jumlah pekerjaan yang wajib dilakukan oleh seorang tenaga pengajar perguruan tinggi sebagai tugas institusional dalam menyelenggarakan fungsi pendidikan tinggi seperti yang dibuat dalam Peraturan Pemerintah No. 5 tahun 1980 pasal 26. Beban tugas dosen dinyatakan dengan Ekivalensi Waktu Mengajar Penuh (EWMP). Menurut UU No. 14 tahun 2005 tentang Guru dan Dosen seorang dosen harus memenuhi EWMP sebesar 12-16 sks per semester.

\section{METODE}

Penelitian ini termasuk jenis penelitian eksplanasi (explanatory research) dengan pendekatan survey yang bertujuan untuk menguji hubungan antar variabel yang dihipotesiskan, yaitu ada tidaknya pengaruh masa kerja $\left(\mathrm{X}_{1}\right)$ dan beban mengajar $\left(X_{2}\right)$ terhadap kinerja professional dosen $(\mathrm{Y})$. Penelitian ini dilakukan pada 11 dosen tetap dan 16 dosen luar biasa prodi. Ekonomi FKIP Universitas Islam Riau pada tahun 2014 Metode analisis yang digunakan dengan menggunakan regresi ganda.

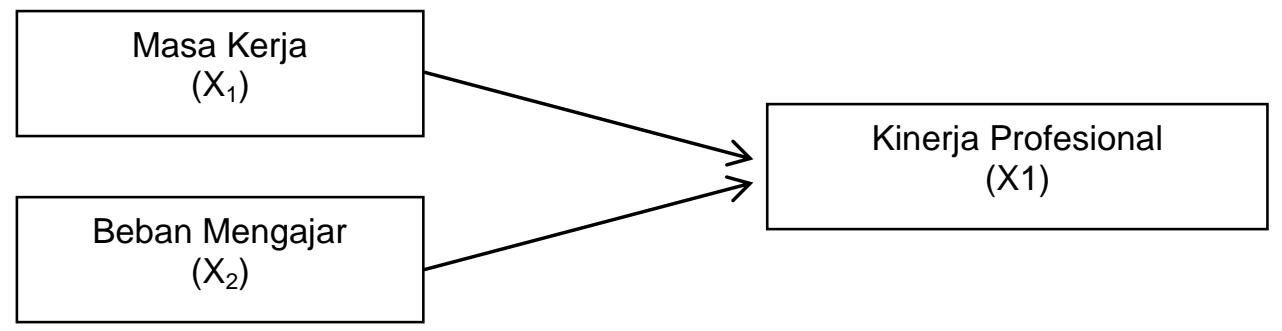

Gambar 1. Kerangka Penelitian

\section{HASIL DAN PEMBAHASAN}

Dari data yang terkumpul kemudian diolah dan diketahui masa

kerja tertinggi 27 tahun dan terendah 5 tahun dengan nilai mean 12,42

Tabel 1. Masa kerja

\begin{tabular}{rccc}
\hline $\mathrm{N}$ & Masa Kerja (tahun) & Frekuensi & Persentase \\
1 & $21,5-27$ & 3 & 11,11 \\
2 & $16-21,5$ & 5 & 18,52 \\
3 & $10,6-16$ & 11 & 40,74 \\
4 & $5-10,5$ & 8 & 29,63 \\
\hline
\end{tabular}

Sumber: data penelitian diolah 2014 
Variabel beban mengajar dosen diukur dengan menggunakan rata-rata beban mengajar dosen selama tiga tahun terakhir yang telah diputuskan ketua program studi ekonomi. Beban mengajar ini dihitung dalam Satuan Kredit Semester (SKS). Dari data yang terkumpul diketahui beban mengajar tertinggi 26 SKS dan terendah 12 SKS dengan nilai mean 21,37

Tabel 2 Distribusi frekuensi beban mengajar

\begin{tabular}{lllll}
\hline No & Kategori & Rentangan SKS & Frekuensi & Persentase (\%) \\
1 & Sangat Tinggi & $>18$ SKS & 17 & 62,94 \\
2 & Tinggi & $13-18$ SKS & 8 & 29,64 \\
3 & Cukup & $7-12$ SKS & 2 & 7,42 \\
4 & Kurang & $\leq 6$ SKS & 0 & 0 \\
\hline
\end{tabular}

Sumber: data olahan 2014

Untuk variable kinerja professional, dari data yang terkumpul diketahui total nilai tertinggi untuk bidang pendidikan dan pengajaran yaitu 59, bidang penelitian dan pengembangan sebesar 27 , bidang pengabdian masyarakat 20 , dan unsur penunjang 29. Sedangkan total nilai terendah untuk bidang pendidikan dan pengajaran yaitu 26 , bidang penelitian dan pengembangan 12, bidang pengabdian masyarakat 4 , dan bidang kegiatan penunjang 10 . Apabila dimasukkan dalam kategori, maka data-data tersebut dapat dilihat pada tabel 3 berikut.

Tabel 3. Distribusi Frekuensi Kinerja Profesionalisme Dosen Bidang Pendidikan dan Pengajaran

\begin{tabular}{lllll}
\hline No & Kategori & Rentangan Skor & Frekuensi & Persentase (\%) \\
1 & Sangat Tinggi & $52-60$ & 2 & 7,69 \\
2 & Tinggi & $42-51$ & 15 & 53,85 \\
3 & Cukup & $32-41$ & 7 & 26,92 \\
4 & Kurang & $22-31$ & 3 & 11,54 \\
5 & Sangat Kurang & $12-21$ & 0 & 0 \\
\hline
\end{tabular}

Sumber: data primer diolah

Tabel 4 Distribusi Frekuensi Kinerja Profesionalisme Dosen Bidang Penelitian dan Pengembangan

\begin{tabular}{lllll}
\hline No & Kategori & Rentangan Skor & Frekuensi & Persentase (\%) \\
1 & Sangat Tinggi & $31-35$ & 0 & 0 \\
2 & Tinggi & $25-30$ & 7 & 26,92 \\
3 & Cukup & $19-24$ & 9 & 30,77 \\
4 & Kurang & $13-18$ & 10 & 38,46 \\
5 & Sangat Kurang & $7-12$ & 1 & 3,85 \\
\hline
\end{tabular}

Sumber: data primer diolah 
Tabel 5 Distribusi Frekuensi Kinerja Profesionalisme Dosen Bidang Pengabdian Masyarakat

\begin{tabular}{lllll}
\hline No & Kategori & Rentangan Skor & Frekuensi & Persentase (\%) \\
1 & Sangat Tinggi & $18-20$ & 2 & 7,7 \\
2 & Tinggi & $15-17$ & 4 & 15,38 \\
3 & Cukup & $12-14$ & 7 & 23,08 \\
4 & Kurang & $8-11$ & 10 & 38,46 \\
5 & Sangat Kurang & $4-7$ & 4 & 15,38 \\
\hline \multicolumn{2}{l}{ Sumber: data primer diolah }
\end{tabular}

Tabel 6 Distribusi Frekuensi Kinerja Profesionalisme Dosen Bidang Kegiatan Penunjang

\begin{tabular}{lllll}
\hline No & Kategori & Rentangan Skor & Frekuensi & Persentase (\%) \\
1 & Sangat Tinggi & $31-35$ & 0 & 0 \\
2 & Tinggi & $25-30$ & 3 & 7,69 \\
3 & Cukup & $19-24$ & 6 & 23,08 \\
4 & Kurang & $13-18$ & 12 & 46,15 \\
5 & Sangat Kurang & $7-12$ & 6 & 23,08 \\
\hline
\end{tabular}

Sumber: data primer diolah

Tabel 7 Hasil analisis regresi ganda hubungan masa kerja dan beban mengajar terhadap kinerja profesionalisme dosen

\begin{tabular}{|c|c|c|c|c|c|}
\hline & \multicolumn{2}{|c|}{$\begin{array}{l}\text { Unstandardized } \\
\text { Coefficients }\end{array}$} & \multirow{2}{*}{$\begin{array}{c}\text { Standardized } \\
\text { Coefficients } \\
\text { Beta }\end{array}$} & \multirow[b]{2}{*}{$t$} & \multirow[b]{2}{*}{ Sig. } \\
\hline & B & $\begin{array}{l}\text { Std. } \\
\text { Error }\end{array}$ & & & \\
\hline (Constant) & 71.180 & 18.741 & & 3.798 & .001 \\
\hline Masa_Kerja & .695 & .220 & .391 & 3.158 & .005 \\
\hline Beban_Mengajar & -1.797 & .662 & -.307 & -2.714 & .013 \\
\hline
\end{tabular}

a Dependent Variable: Kinerja Professional Dosen

Berdasarkan hasil uji regresi di atas, maka diperoleh nilai konstanta 71,180 , nilai koefisien regresi variabel masa kerja $\left(X_{1}\right)$ sebesar 0,695 dan nilai koefisien regresi variabel beban mengajar $\left(\mathrm{X}_{2}\right)$ sebesar -1,797, sehingga apabila dimasukkan dalam fungsi asli regresi maka diperoleh persamaan sebagai berikut.

$Y=71,180+0,695 X_{1}-1,797 X_{2}$

Berdasarkan hasil analisis data diatas menunjukan adanya bukti bahwa ada pengaruh positif signifikan masa kerja terhadap kinerja profesionalisme dosen. Hal tersebut tampak dari hasil analisis regresi ganda yang menunjukkan koefisien positif variable masa kerja sebesar 0,695 . Hasil tersebut juga menunjukan adanya bukti bahwa ada pengaruh negatif signifikan beban kerja terhadap kinerja profesionalisme dosen. Hal tersebut tampak dari hasil analisis regresi ganda yang menunjukkan koefisien negatif variable beban mengajar sebesar $-1,797$

Hasil dari penelitian ini menunjukkan bahwa seorang dosen yang memiliki masa kerja lebih lama memperlihatkan hasil kinerja yang lebih baik pula. Hal ini sejalan dengan pernyataan Widjaja (1986:68) bahwa masa kerja dapat memberikan kemahiran, sehingga makin lama orang bekerja dapat makin cakap dan terampil di bidang pekerjaan itu. Dosen 
yang memiliki masa kerja cukup lama akan memiliki lebih banyak pengalaman, sehingga akan memiliki penguasaan materi perkuliahan atau ilmu pengetahuan yang baik dan maksimal pada bidang yang ia ajarkan kepada mahasiswanya. Dengan masa kerja yang cukup lama, tentunya dosen akan mampu mengembangkan dan menerapkan strategi pembelajarannya dengan baik.

Hasil penelitian ini juga membuktikan teori Wright (1936) "learning curve theory" yang mengatakan bahwa semakin lama seseorang mengerjakan pekerjaan yang sama, semakin ahli ia mengerjakan pekerjaan itu, dan semakin sedikit waktu yang ia butuhkan untuk mengerjakan setiap unitnya. Atau dengan kata lain, semakin sering seseorang menghadapi suatu masalah, semakin berpengalaman ia menangani masalah tersebut. Semakin lama menjadi dosen, maka dosen tersebut akan memiliki kinerja yang lebih baik. Dari situ, hendaknya dosen senior meningkatkan aktifitasnya dalam membimbing dosen yang lebih yunior. Hasil penelitian ini menunjukkan bahwa dosen yang memiliki beban mengajar tinggi cenderung menunjukkan kinerja profesionalisme yang rendah. Kinerja profesionalisme dosen program studi pendidikan ekonomi FKIP UIR dipengaruhi oleh beban mengajar mendukung hasil penelitian Lisnayeti (2006) yang menghasilkan bahwa beban kerja berhubungan dengan kinerja dosen. Beban kerja yang tinggi menyebabkan berkurangnya kesempatan dosen dalam menyiapkan materi, mempersiapkan metode dan media dalam pengajaran. Selain itu, beban mengajar yang tinggi juga menyebabkan berkurangnya waktu yang bisa digunakan dosen dalam meningkatkan kemampuan dan pengetahuan individu dosen itu sendiri, seperti kemampuan menguasai bahasa asing, waktu untuk mempersiapkan dan melaksanakan penelitian dan pengabdian kepada masyarakat.

Hasil penelitian ini juga sejalan dengan pernyataan Legawati (1996:42) bahwa dosen yang mempunyai beban mengajar terlalu banyak dan melebihi ketentuan jam wajib yang telah diperhitungkan akan mempengaruhi daya tahan fisik dosen. Di samping itu dosen tidak sempat lagi mempersiapkan materi pengajaran secara sempurna yang pada gilirannya secara keseluruhan beban mengajar akan mempengaruhi kemampuan mengajarnya, karena pengajaran menjadi tidak terprogram dengan baik. Dengan demikian, semakin banyak beban mengajar dosen, maka akan semakin rendah kinerja dosen tersebut.

\section{SIMPULAN}

Berdasarkan temuan diatas dapat disimpulkan bahwa terdapat pengaruh positif masa kerja terhadap kinerja professional dosen program studi pendidikan ekonomi FKIP UIR. Sedangkan untuk variable beban mengajar memiliki pengaruh negative terhadap kinerja professional dosen.

\section{DAFTAR PUSTAKA}

Alim, Nur.2004.Hubungan Antara Tingkat Pendidikan, Pengalaman Kerja, Kinerja Akademik, dan Pemahaman terhadap Tugas dengan Kinerja Manajerial Dosen yang Diberi Tugas sebagai Administrator pada STAIN di Sulawesi.Tesis tidak diterbitkan.Program Pasca Sarjana Universitas Negeri Malang

Arikunto, Suharsini. 2002. Prosedur Penelitian Suatu Pendekatan Praktek. Jakarta: Rineka Cipta

Departemen Pendidikan Nasional.2003.Undang-Undang Republik Indonesia Nomor 20 Tahun 2003 tentang Sistem Pendidikan

Nasional.Jakarta:Depdiknas 
Gagne, Robert. 1983. The Condition of Learning. Japan: Holt Saunders.

Gonzalez, A., \& Wolters, C. 2006. The relation between perceived parenting practices andachievement motivation in mathematics. Journal of Research in Childhood Education,21, 203-217

Harter, S. 1998. The development of self-representations. In Damon, W., \& Eisenberg, N. (ed.), Handbook of child psychology, 3 (5), 553-617. New York: John Wiley and Sons.

Jewell,L \& Siegall,M.1998. Psikologi Industri/Organisasi Modern: Psikologi Terapan Untuk Memecahkan Berbagai Masalah di Tempat Kerja, Perusahaan,Indusrti, dan Organisasi.Edisi 2.Alih Bahasa A. Handyana Pudjaatmaka \& Meitasari.Jakarta : Penerbit Arcan

Kinicki, Angelo dan Robert Kreitner. 2003. Organizational behavior Key Concept, Skills \& Best Pratices. Boston: Mc.Graw Hill

Krech, David , Richard S. Crutchfield, Norman Livson. 1973. Elements of Perception. New York: Knopf publishing

Lisnayetti,Mubasysyir H. 2006. Beban Kerja dan Kinerja Dosen Poltekes Padang (Online),(http://Irc-

Kmpk.ugm.ac.id/id/upPDF/working

No.3 Lisnayetti.11-06.pdf)

Miller, Danny, dkk.1993. Celebrating the Essential: the Impact of
Performance of the Functional Favoritsm of CEO'S in Two Contexts. Jurnal of Management (JOM), Vol:23, 155:2,P:147-168

Ranuwihardjo, Sukadji.1990. Kebijaksanaan Umum Pengembangan IImu Pengetahuan dan Teknologi di Perugruan Tinggi 1985-1995. Jakarta: Direktorat Pembinaan Penelitian dan Pengembangan pada Masyarakat Dirjen Dikti Depdikbud

Seniati, Ali Nina L \& Silalahi,Corina D.2001. Hubungan antara Persepsi dan Diskrepansi Harapan, Persepsi, Karyawan atas Pengelolaan Sumber Daya manusia dalam Organisasi dengan Komitmen Karyawan pada Organisasi. Artikel penelitian dalam jurnal "MAKARA" Vol 5, No 1, Juni 2001,Hal 9-17. Jakarta: Lemlit UI

Soeharto,Karti.1992.Keterampilam Berkomunikasi Dosen-Dosen Fakultas IImu Pendidikan IKIP Surabaya dalam Kegiatan Pembelajaran Ditinjau dari Latar:Masa Kerja, Jabatan/Golongan, Pendidikan, dan Jenis Kelamin. Tesis tidak diterbitkan.Program Pasca Sarjana Universitas Negeri Malang

Owens,RG.1991.Organizational Behavior in Education.New Jersey: Prentice Hall Robbins, Stephen.1996. Perilaku Organisasi. Edisi Bahasa Indonesia. Jilid 1. Jakarta: PT. Prenhallindo 